\title{
Efficiency of Foreign Exchange Markets in Sub-Saharan Africa in the Presence of Structural Break: A
} Linear and Non-Linear Testing Approach

\author{
Adeyeye Patrick Olufemi ${ }^{1 *}$, Aluko Olufemi Adewale², Migiro Stephen Oseko ${ }^{1}$ \\ 1University of KwaZulu-Natal, Westville, Durban, South Africa \\ ${ }^{2}$ University of Ilorin, Ilorin, Kwara State, Nigeria \\ adeyeyepo@gmail.com*, olufemiadewale6@gmail.com, stephen410@gmail.com
}

\begin{abstract}
This study examines the efficiency of foreign exchange (forex) market of 10 selected countries in sub-Saharan Africa in the presence of structural break. It uses data on the average official exchange rate of currencies of the selected countries to the US dollar from November 1995 to October 2015. This study employs Perron unit root test with structural break to endogenously determine the break period in the forex markets. It also employs the Kim wild bootstrap variance ratio test and BDS independence test to detect linear and nonlinear dependence in forex market returns respectively. In the full sample period, the Kim wild bootstrap joint variance ratio test shows that only two forex markets are efficient while the BDS independence test reports that all the forex markets are not efficient. The subsample period analysis indicates that the efficiency of the majority of the forex markets is sensitive to structural break, thus providing evidence in support of the adaptive market hypothesis. This study suggests that ignoring structural break and nonlinearity of returns may lead to misleading results when testing for market efficiency.
\end{abstract}

Keywords: Efficiency, foreign exchange market, structural break, sub-Saharan Africa

\section{Introduction}

Investors in the foreign exchange (forex) market are concerned about the efficiency of the market in order to determine whether there is a possibility to outperform the market based on past market information. Meese and Rogoff (1983) pioneered research into the predictability of forex rate based on a random walk model. The ability to predict forex rate behaviour supports the assertion of the long-run purchasing power parity model. In empirical literature, the quest to determine the predictability of the forex market is underpinned to the efficient market hypothesis (EMH) propounded by Fama (1970) which suggests that a market is efficient when future returns in the market cannot be predicted using past market information or events. Currency traders in an efficient forex market cannot use technical analysis to earn returns above the average market returns because forex rates follow a random walk (non-predictable patterns). Baffes (1994) argues that an efficient forex market does not mean forex are not predictable, but it implies that arbitrage opportunities cannot be exploited. Based on the dependence structure of increment series, Campbell, Lo and Mackinlay (1997) distinguish the random walk model into three variant models namely: Random Walk 1 (RW1), Random Walk 2 (RW2) and Random Walk 3 (RW3). RW1 model assumes that price increments are independently and identically distributed with a zero mean and constant variance. RW2 model assumes that price increments are independently but not identically distributed with zero mean and constant variance. RW3 model assumes that price increments are not correlated.

The efficiency of the forex market can be determined by testing the martingale hypothesis and the martingale difference hypothesis (MDH) which are lower versions of the random walk hypothesis. The martingale hypothesis states that the best forecast of tomorrow's price is the price of today while MDH posits that the best prediction of tomorrow's return is today's return. The forex market is said to be efficient when either the martingale hypothesis or MDH holds. An efficient market does not allow investors to predict future gains in the market due to the randomness of returns. Escancianio and Labato (2009) argue that a financial time series is a martingale if it corresponds to RW2. The RW2 model is appropriate when financial time series exhibits volatility. Numerous studies such as Wright (2000), Belarie-Franch and Opong (2005), Yang, Su and Kolari (2008), Escanciano and Lobato (2009), Lazăr, Todea and Filip (2012), Charles, Darné and Kim (2012), Azar (2014), Salisu, Oloko and Oyewole (2016) tested for MDH rather than martingale hypothesis. Escanciano and Labato (2009) argue that it is easier to deal with returns because price tends to be non-stationary, thus making it common to test for MDH when testing the efficiency of the forex market. Also, the test for MDH has gained much attention because forex markets tend to be volatile in nature. Ignoring structural break when testing for MDH may render the results misleading (Salisu et al., 2016; Salisu \& Ayinde, 2016). Not much 
attention has been given to the efficiency of forex markets in African countries. Therefore, this study tests the forex market efficiency of 10 selected sub-Saharan African countries taking into account the presence of structural break in the markets. It is worthy of note that failure to consider the nonlinearity of returns can lead to misleading conclusion on the efficiency of the forex markets. This study provides answers to these empirical questions: (i) Does Lo (2004)'s adaptive market hypothesis holds in the selected forex markets? (ii) Is the nonlinearity of forex rate returns a consideration for the test of the efficiency of the selected forex markets? Therefore, this study would validate whether testing for structural break and nonlinearity are important for testing efficiency of forex market. The rest of this study is outlined as follows: Section 2 deals with the literature review, Section 3 provides the data and preliminary analyses, and Section 4 and Section 5 present the empirical results and conclusion respectively.

\section{Literature Review}

Myriad of studies have provided evidence on the efficiency of the forex market by examining whether forex rate is a martingale or random walk. Yang et al. (2008) noted that martingale and random walk have been used interchangeably despite not being absolutely synonymous. A series is martingale if innovations or error terms are independent but not identically distributed while it is a random walk if error terms are independent and identically distributed. The pioneering work of Meese and Rogoff (1983) showed that the behaviour of forex rate conforms to the random walk hypothesis (RWH). Liu and He (1991) employed the variance ratio (VR) test and observed that there are autocorrelations of weekly increments in the nominal forex rate series between August 7, 1974 and March 29, 1989, thus the study rejects the MDH. Ogiogio (1994) found evidence to negate RWH using monthly data of the Nigerian forex market from 1989 to 1993. Aron (1997) used co-integration methodology to examine whether forex returns are predictable in South Africa. Utilising monthly parallel market and official forex rates, the study found that forex returns are predictable, thus affirming that the forex market of South Africa is not weak-form efficient. Hong and Lee (2003) applied the generalized spectral test on five major currencies and found that forex returns are frequently not serially correlated.

Wickremasinghe (2004) tested the weak-form and semi-strong efficiency of the forex market of Sri Lanka against the Japanese yen, British pound, US dollar, French franc, Indian rupee and German mark for the period January 1986-November 2000. With the aid of unit root and cointegration tests, the study found evidence in support of the weak-form efficiency and against the semi-strong efficiency. Belaire-Franch and Opong (2005) used the VR test based on ranks and signs on Euro exchange rates and offered evidence in support of MDH. Yang et al. (2008) accepted MDH for the Euro relative to the 3 major currencies (Japanese yen, British pound and US dollar) and also observed nonlinear predictability in the Euro against several smaller currencies. Sifunjo, Ngugi, Ganesh and Gituro (2008) employed a battery of tests consisting of run, unit root and Ljung-Box Q-statistic tests to examine whether returns on Kenyan shillings to US dollar are predictable and the findings rejected the MDH. Al-Khazali and Pyun (2009) examined RWH and MDH for the Australian dollar and currencies of 7 Asian currencies against the Euro, US dollar and Japanese yen. The results rejected both hypotheses for all the currencies over the period January 4, 1993 to December 31, 2008. Charles and Darné (2009) tested the random walk behaviour of daily and weekly data of Euro against currencies of 11 countries from January 4, 1999 to May 30, 2008. Using VR tests, the RWH was accepted for 8 countries (Australia, Canada, Japan, United Kingdom, US, New Zealand, Korea and Switzerland). However, RWH was rejected for daily data for Singapore and Norway and accepted for their weekly data while it was rejected for Sweden for both data frequencies. Azad (2009) utilised daily and weekly frequency post-Asian crisis spot exchange rate data of 12 Asia-Pacific forex markets from January 1998 to July 2007. The VR provided mixed results. For the daily data, majority of the forex rates exhibited martingale behaviour while the test on weekly data showed that majority of the forex rates are not martingale. This study shows that the randomness of forex rates may be dependent on data frequency.

Gradojević, Djaković and Andjelić (2010) invalidated RWH for the Euro/Serbian dinar between January 2005 and December 2008 using VR tests. Chiang, Lee, Su and Tzou (2010) employed series of VR tests to examine the efficiency of the forex markets of Japan, South Korea, Taiwan and Philippines. The results provided evidence in support of RWH in the all the forex markets except for Taiwan. Kumar (2011) applied VR tests on the Indian rupee against the IMF's Special Drawing Rights in indexed form between April 1993 and June 2010 
and found that the Indian forex market is weak-form inefficient, thus rejecting RWH. Charles et al. (2012) used daily and weekly data to examine the returns predictability of the Australian dollar, Canadian dollar, Japanese yen and Swiss franc against the US dollar from January 2, 1974 to July 17, 2009. Employing the wild bootstrap automatic VR test, generalized spectral test and consistent tests, the findings suggested that forex returns are predictable from time to time depending on the changing market conditions. The study offered support to the adaptive market hypothesis put forward by Lo (2004). Lazăr, Todea and Filip (2012) evaluated the impact of the 2008 global financial crisis on the forex market efficiency of 6 Central and Eastern European (CEE) countries from January 2004 to February 2011. Adopting the generalized spectral test in a rolling window approach, the study showed that the global financial crisis negatively affected the efficiency of most of the CEE forex markets. Using Escanciano and Lobato automatic Box-Pierce $Q_{p}$, Nankervis and Savin generalized Andrews-Ploberger and Deo robust Durlauf tests, Cheung, Su and Choo (2012) found that majority of the Euro forex markets are weak-form efficient.

Czech and Waskowski (2012) utilised uncovered interest rate parity regression and orthogonality test of the forward rate forecast error to test the efficiency of US dollar/euro market between January 1999 to December 2010 and found that the market is not efficient. Phillips and Jin (2013) applied the KolmogorovSmirnov and Cramér-von Mises tests on major forex rates data and found strong evidence in support of the martingale hypothesis. Tweneboah, Amanfo and Kumah (2013) examined the behaviour of Ghanaian cedi/US dollar between January1963 and May 2013 using the conventional VR test and the VR test based on ranks and signs and invalidate the RWH. Shalari and Stringa (2013) tested the efficiency of the Albanian forex market by using data on the Albanian Lekë/Euro between January 1, 2002 and December 31, 2012. Employing the Kolmogorov-Smirnov-Lilliefors and Shapiro-Wilk tests for normality, the study found that the forex rate is not consistent with the martingale process, thus suggesting that the market is not weak-form efficient. Mbululu, Auret and Chiliba (2013) showed that RWH is rejected for daily returns on US dollars/Zambian kwacha between August 1, 2003 to December 31, 2005 using the conventional VR and the ranks and signs VR tests. Mabakeng and Sheefeni (2014) provided evidence based on unit root tests that the Nambian forex market was weak-form efficient between January 1993 and December 2011.

Azar (2014) assessed the martingale behaviour of the Lebanese pound against the Australian dollar, Canadian dollar, Swiss franc, Euro, British pound and Japanese yen from January 4, 2010 to January 31, 2014 using the VR test. The study provided support for MDH. Almudhaf (2014) investigated the randomness of currencies of CIVETS (Colombia, Indonesia, Vietnam, Egypt, Turkey and South Africa) relative to the US dollar using weekly data from February 2, 2007 to April 13, 2012. The results of the VR tests indicated the forex rates of all the countries follow a random walk except Vietnam and Egypt. Rasekhi and Shahrazi (2014) tested for the weakform efficiency of the Iranian forex market under fixed and managed float exchange rate regimes. The results showed that the market is more efficient in the managed float exchange regime. Katusiime, Shamsuddin and Agbola (2015) investigated the efficiency of the Ugandan forex market from January 1994 to June 2012 using a battery of variance ratio tests. It found that the market is not weak-form efficient. Salisu et al. (2015) examined the MDH in currencies of 9 countries in the Asia-Pacific region against the Euro on weekly basis from April 1, 2005 to September 12, 2014. Utilising the wild bootstrap automatic VR test and wild bootstrap generalized spectral test, the results showed that all the currencies aligned to MDH over the whole period. However, after accounting for structural break, the results revealed that the South Korean won rejected MDH prior to its break date while the Chinese yuan did not support the MDH after its break date. Salisu and Ayinde (2016) tested for MDH in South Africa and Nigeria using the weekly data of their currencies relative to euro, dollar and pound sterling between December 14, 2001 and September 26, 2014. The study found that the forex market of South Africa is more efficient than the Nigerian forex market.

\section{Data and Preliminary Analyses}

This study constructs a sample consisting of forex markets of 10 sub-Saharan African countries. Data on the average official exchange rates of the currencies of these countries relative to the US dollar from November 1995 to October 2015 (i.e. 1995M11 - 2015M10) were obtained from the World Bank Global Economic Monitor. Table 1 presents the description of the currencies. 
Table 1: Currency Description

\begin{tabular}{lll}
\hline Currency & ISO 4217 Code & Country \\
\hline Burundian franc & BIF & Burundi \\
Ghana cedi & GHS & Ghana \\
Dalasi & GMD & The Gambia \\
Malagasy ariary & MGA & Madagascar \\
Ouguiya & MRO & Mauritania \\
Mauritian rupee & MUR & Mauritius \\
Mozambican metical & MZN & Mozambique \\
Leone & SLL & Sierra Leone \\
Ugandan shilling & UGX & Uganda \\
Zambian kwacha & ZMW & Zambia \\
\hline
\end{tabular}

Source: Compiled by authors

The return series is obtained from the forex rates and is calculated as:

$R_{t}=100 \times \Delta \ln \left(E_{t}\right)$

Where $R_{t}$ is forex return at month $t, \Delta$ is the first difference operator, $\ln$ is natural logarithm and $E_{t}$ is the exchange rate at month $t$.

Figure 1: Graph of Return series
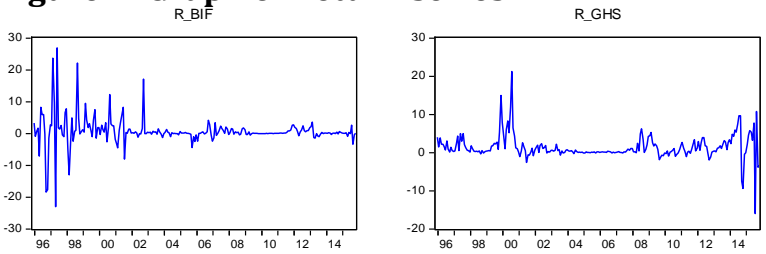

RMRO

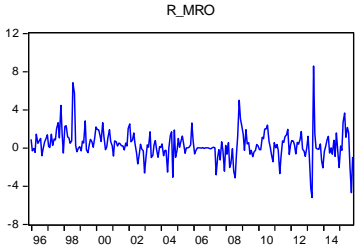

R_UGX

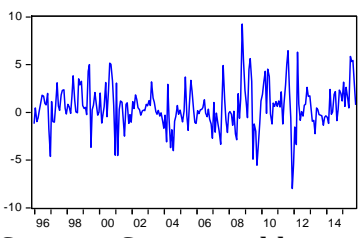

R MUR

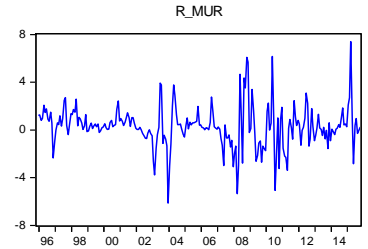

R_ZMW

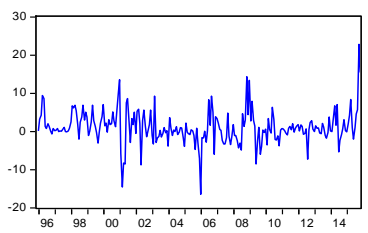

Source: Computed by authors
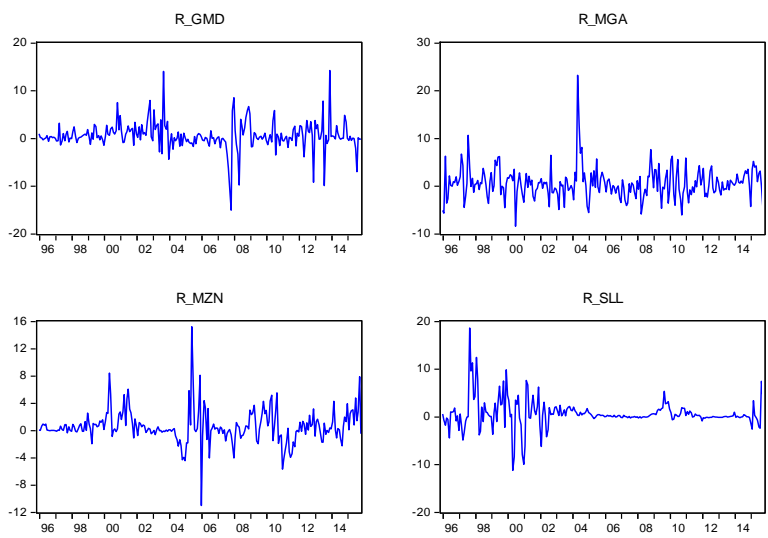

Table 2: Descriptive Statistics

\begin{tabular}{llllllll}
\hline Series & Mean & Maximum & Minimum & Std. Dev. & Skewness & Kurtosis & Jarque-Bera \\
\hline R_BIF & 0.738672 & 26.91585 & -23.00850 & 4.412176 & 0.895865 & 18.79233 & $2515.553^{*}$ \\
R_GHS & 1.381807 & 21.23800 & -16.03053 & 3.089346 & 1.129946 & 15.98617 & $1730.238^{*}$ \\
R_GMD & 0.586438 & 14.26651 & -15.01448 & 2.964887 & -0.206821 & 10.96015 & $632.7043^{*}$ \\
R_MGA & 0.566421 & 23.22857 & -8.395489 & 3.273893 & 1.664295 & 12.57926 & $1024.132^{*}$ \\
R_MRO & 0.342758 & 8.600377 & -5.175366 & 1.525883 & 0.785706 & 8.986141 & $381.4362^{*}$ \\
R_MUR & 0.283042 & 7.393133 & -6.139624 & 1.712627 & 0.208919 & 6.327144 & $111.9762^{*}$ \\
R_MZN & 0.575632 & 15.22991 & -10.98918 & 2.392248 & 0.939289 & 11.24251 & $711.7025^{*}$ \\
R_SLL & 0.632990 & 18.61851 & -11.22481 & 2.990893 & 0.981953 & 11.91884 & $830.5516^{*}$ \\
R_UGX & 0.535913 & 9.258722 & -7.980215 & 2.251793 & 0.139417 & 4.776655 & $32.20776^{*}$ \\
R_ZMW & 1.067860 & 22.80642 & -16.44690 & 4.283228 & 0.500054 & 7.660162 & $226.2266^{*}$ \\
\hline
\end{tabular}

Note: * implies rejection of null hypothesis of normal distribution at $1 \%$ significance level.

Source: Computed by authors 
From Table 2, the mean values of return series for all the currencies are positive, thus implying that forex rates return of the currencies under consideration depreciated on the average over the period under review. GHS and MUR have the highest and lowest mean values respectively in terms of returns. BIF records the highest maximum and lowest minimum values of returns among the currencies, thus indicating that it has the largest variance. The standard deviation indicates that R_BIF and R_MRO have the highest and lowest statistic respectively, thus implying that returns on BIF is the most volatile while returns on MRO is the least volatile. This further implies that the Burundian forex market is the most risky market while the Mauritanian forex market has the lowest risk. The skewness statistic shows that all the return series are positively skewed except R_GMD. The Kurtosis coefficient indicates that all return series have a leptokurtic (high-peaked and fat-tailed) distribution. The Jarque-Bera statistic shows that all return series are not normally distributed.

Table 3: ARCH LM Test Results

\begin{tabular}{lll}
\hline Series & ARCH LM(5) & ARCH LM(10) \\
\hline R_BIF & $7.660413^{*}$ & $5.891018^{*}$ \\
R_GHS & $6.994783^{*}$ & $4.967068^{*}$ \\
R_GMD & $3.886439^{*}$ & $2.248240^{*}$ \\
R_MGA & $3.180009^{*}$ & $1.640611^{* * *}$ \\
R_MRO & $6.882392^{*}$ & $3.629929^{*}$ \\
R_MUR & $5.853200^{*}$ & $3.196870^{*}$ \\
R_MZN & $2.369036^{* *}$ & $6.504206^{*}$ \\
R_SLL & $12.51853^{*}$ & $6.519923^{*}$ \\
R_UGX & $6.106988^{*}$ & $3.392364^{*}$ \\
R_ZMW & $6.576927^{*}$ & $3.372881^{*}$ \\
\hline
\end{tabular}

Note: *,** and ${ }^{* * *}$ implies rejection of null hypothesis of homoscedasticity at $1 \%, 5 \%$ and $10 \%$ significance level respectively and F-statistic is reported for the ARCH LM test.

Source: Computed by authors

The ARCH LM test rejects the null hypothesis of homoscedasticity in all return series at lags 5 and 10, thus confirming the presence of conditional heteroscedascity in all return series. This implies that the return series exhibit volatility clustering and confirms that all the forex markets are volatile. This study accounts for the break period/point in each return series so as to determine when structural change occurred in the forex market. It employs the Perron (2006) unit root test which endogenously determines the most significant break period in the return series in an Innovative Outlier (IO) model. The unit root test is performed using the $t$-statistic for testing the null hypothesis that $\delta=1$ in the regression model below.

$y_{t}=\mu+\theta D U_{t}+\beta t+\lambda D T_{t}^{*}+\gamma D\left(T_{b}\right)_{t}+\delta y_{t-1}+\sum_{i=1}^{k} c_{i} \Delta y_{t-1}+\varepsilon_{t}, \varepsilon_{t} \sim I I D\left(0, \sigma^{2}\right)$

Where $D U_{t}=1, D T_{t}^{*}=t-T_{b}$ if $t>T_{b}$ and 0 otherwise, $D\left(T_{b}\right)_{t}=1$ if $t=T_{b}+1$ and 0 otherwise.

Table 4: Unit Root Test with Structural Break

\begin{tabular}{llll}
\hline Series & Break Period & Coefficient & $\boldsymbol{t}$-statistic \\
\hline R_BIF & 1998M07 & -0.970580 & $-15.463718^{*}$ \\
R_GHS & $2000 \mathrm{M} 06$ & -0.755491 & $-13.049654^{*}$ \\
R_GMD & $2007 \mathrm{M} 09$ & -0.934440 & $-14.861336^{*}$ \\
R_MGA & $2004 \mathrm{M} 03$ & -0.688797 & $-12.578222^{*}$ \\
R_MRO & $2008 \mathrm{M} 09$ & -0.770496 & $-12.256203^{*}$ \\
R_MUR & $2010 \mathrm{M} 04$ & -0.585005 & $-10.170324^{*}$ \\
R_MZN & $2005 \mathrm{M} 04$ & -0.663189 & $-11.815286^{*}$ \\
R_SLL & $1997 \mathrm{M} 12$ & -0.672087 & $-10.985025^{*}$ \\
R_UGX & $2008 \mathrm{M} 09$ & -0.637910 & $-10.783004^{*}$ \\
R_ZMW & $2000 \mathrm{M} 11$ & -0.641189 & $-10.413725^{*}$ \\
\hline
\end{tabular}

Note: * denotes t-statistic exceeds $1 \%$ critical value. Also, the critical value is obtained from Table 1 (e) model 2 in Perron (1997).

Source: Computed by authors 
Table 4 shows that all the forex rates return series are stationary series. Based on the identified structural break period by the Perron (2006) unit root test with structural break, this study divides the full sample period into pre-break and post-break periods. The pre-break period spans from November 1995 to the month before structural break period while the post-break period extends from the month after the structural break occurred to October 2015. Table 3 reports the time span for the pre and post-break periods for each return series.

Table 5: Subsample Periods for Return Series

\begin{tabular}{lll}
\hline Series & Pre-break Period & Post-break Period \\
\hline R_BIF & 1995M11 - 1998M06 & 1998M08 - 2015M10 \\
R_GHS & 1995M11 - 2000M05 & 2000M07 - 2015M10 \\
R_GMD & 1995M11 - 2007M08 & 2007M10 - 2015M10 \\
R_MGA & 1995M11 - 2004M02 & 2004M04 - 2015M10 \\
R_MR0 & 1995M11 - 2008M08 & 2008M10 - 2015M10 \\
R_MUR & 1995M11 - 2010M03 & 2010M05 - 2015M10 \\
R_MZN & 1995M11 - 2005M03 & 2005M05-2015M10 \\
R_SLL & 1995M11 - 1997M11 & 1998M01 - 2015M10 \\
R_UGX & 1995M11 - 2008M08 & 2008M10 - 2015M10 \\
R_ZMW & 1995M11-2000M10 & 2000M12 - 2015M10 \\
\hline
\end{tabular}

Source: Compiled by authors

\section{Empirical Results}

When forex rate returns are non-predictable, it can be said that the forex market follows a martingale difference sequence (MDS) process. Returns follow a MDS process when the best prediction of tomorrow's return is the return of today and it is impracticable to use linear and non-linear combinations of past returns to forecast future returns. The MDS process has implication for the efficiency of the forex market. The martingale stochastic model is suitable for determining whether returns are predictable (Lazăr, Todea \& Filip, 2012). The model can be stated as:

$E\left(R_{t+1} \mid R_{t}, R_{t-1}, \ldots \ldots \ldots . R_{t-n}\right)=0$

Where $R_{t+1}$ is future return, $R_{t}$ is current return, $R_{t-1}$ is immediate past return, $R_{t-n}$ is return lagged by $n$ periods, $n$ is the lag operator.

The Kim (2006) wild bootstrap joint variance ratio (VR) test and BDS Independence test with bootstrapping are used to test whether return follows the MDS process.

Kim (2006) Wild Bootstrap Joint VR Test: The Kim (2006) wild bootstrap joint VR test was performed to confirm whether there is linear dependence in the return series. This test determines whether a set of VR's over a number of holding periods are jointly equivalent to one. When VR is equal to 1 or not statistically different from 1, it implies that the return series has martingale behaviour and the forex market is weak form efficient. The Kim (2006) wild bootstrap joint VR test follows three steps:

a. Construct a bootstrap sample of $T$ observations $x_{t}^{*}=\eta_{t} x_{t}(t=1, \ldots, T)$ where $\eta_{t}$ is a random sequence with zero mean and unit variance.

b. Calculate the maximum absolute value $\left(\mathrm{MV}^{*}\right)$ with $x_{t}^{*}$.

c. Repeat a and b sufficiently $m$ times to form a bootstrap distribution of $\left\{M V^{* j}\right\}_{j=1}^{m}$.

The holding periods for the subsample and full sample periods was set at 2, 4, 8 and 16. The test hypothesis is that the series is martingale and this hypothesis can only be rejected when the p-value of $\mathrm{MV}^{*}$ is not greater than 0.1. Table 6 reports the results of the Kim (2006) wild bootstrap joint VR test.

From Table 6, R_BIF and R_GHS follow the MDS process in the sub-sample and full sample periods. Conversely, R_GMD and R_MGA do not follow the MDS process in the sub-sample and full sample periods. The hypothesis that R_MRO is a martingale is rejected in the pre-break period but is accepted after the break. However, R_MRO is not a martingale in the full sample period. R_MUR and R_MZN fail to invalidate MDH in the sub-sample periods but rejects MDH in the full sample period. R_SLL and R_ZMW are martingale prior to 
structural break; however, they do not exhibit martingale behaviour subsequent to structural break. In the full sample period, R_SLL and R_ZMW reject MDH. R_UGX is non-martingale in the pre-break and full sample periods but a martingale in the post-break period. The results confirm that the linearity of returns in most forex markets is sensitive to structural market. This implies that the linear dependence of returns in most of the forex markets changes with time.

Table 6: Kim (2006) Wild Bootstrap Joint VR Test Results

\begin{tabular}{llll}
\hline Series & Pre-break Period & Post-break Period & Full Period \\
\hline R_BIF & {$[1.156574]$} & {$[2.272798]$} & {$[1.693409]$} \\
& $(0.4910)$ & {$[0.1410)$} & $(0.1730)$ \\
R_GHS & {$[1.328302]$} & {$[1.507687]$} & {$[1.623171]$} \\
& $(0.3460)$ & $(0.2840)$ & $(0.1790)$ \\
R_GMD & {$[2.660273]$} & {$[2.609951]$} & {$[3.379695]$} \\
& $(0.0400)^{* *}$ & $(0.0330)^{* *}$ & $(0.0110)^{* *}$ \\
R_MGA & {$[3.055487]$} & {$[2.595752]$} & {$[3.789037]$} \\
& $(0.0230)^{* *}$ & $(0.0430)^{* *}$ & $(0.0000)^{*}$ \\
R_MRO & {$[3.259055]$} & {$[1.639891]$} & {$[2.764543]$} \\
& $(0.0060)^{*}$ & $(0.2070)$ & $(0.0160)^{* *}$ \\
R_MUR & {$[1.977614]$} & {$[1.894660]$} & {$[2.740733]$} \\
& $(0.1200)$ & $(0.1190)$ & $(0.0290)^{* *}$ \\
R_MZN & {$[2.097665]$} & {$[2.299809]$} & {$[2.534291]$} \\
& $(0.2800)$ & $(0.1160)$ & $(0.0340)^{* *}$ \\
R_SLL & {$[1.381913]$} & {$[2.950385]$} & {$[3.032697]$} \\
& $(0.4820)$ & $(0.0770)^{* * *}$ & $(0.0250)^{* *}$ \\
R_UGX & {$[3.054371]$} & {$[1.977919]$} & {$[3.424977]$} \\
& $(0.0270)^{* *}$ & $(0.1470)$ & $(0.0040)^{*}$ \\
R_ZMW & {$[1.942606]$} & {$[3.634135]$} & {$[3.768713]$} \\
& $(0.1490)$ & $(0.0020)^{*}$ & $(0.0020)^{*}$ \\
\hline
\end{tabular}

Note: ${ }^{*}, *$ and $* * *$ indicate the rejection of null hypothesis at $1 \%, 5 \%$ and $10 \%$ significance level respectively, $\mathrm{MV}^{*}$ in [ ] and p-value in ( ).

Source: Computed by authors

BDS Independence Test: The BDS Independence test developed by Brock, Dechert, Scheinkman and LeBaron (1996) was performed to test for nonlinear dependence in the return series. The null hypothesis is that the series are independent and identically distributed (i.i.d). The rejection of the null hypothesis is an indication of nonlinear dynamics in the return series. Structural changes in the data series can lead to the false rejection of the null hypothesis (Pandey, Kohers \& Kohers, 1998; Hsieh, 1991). In other words, failure to account for presence of structural break in data series when applying the BDS Independence test may produce biased results. Therefore, accounting for structural break in the return series in this study makes the results of the BDS independence test reliable. Brock, Hsieh and LeBaron (1991) point out that the BDS independence test may not be reliable when applied to observations less than 500. Belaire-Franch and Contreras (2002) suggest that the problem of unreliability in small samples can be solved by bootstrapping. The observations for each selected forex market is less than 500. Therefore, the BDS independence test was performed with bootstrapping using correlation dimension $(\mathrm{m})$ from 2 to 6 on residuals extracted from an AR(2) model ${ }^{1}$ estimated with the least squares method. The epsilon $(\varepsilon)^{2}$ for the test was specified using standard deviations method. Table 7 presents the results of the BDS independence test with bootstrapping. From Table 7, it can be deduced that the return series for all the forex markets provide evidence of nonlinearity in the full period and this indicates that the return generating process of returns in all the forex markets is chaotic. In the pre-break period, all the forex market returns show evidence of nonlinearity. In the post-break period, R_BIF confirms absence of nonlinearity and R_UGX shows weak evidence of nonlinearity. The forex market returns for the remaining markets give strong evidence of nonlinearity. It can be seen that

\footnotetext{
${ }^{1} \mathrm{An} \mathrm{AR}(\mathrm{p})$ is adequate to remove the linearity of the data structure. Hsieh (1991) and Gilmore (1996) found that the standardized residuals filtered from a GARCH (p, q) model failed to fully capture the linearity of the data structure.

${ }^{2}$ Hsieh and LeBaron (1988) suggest that $\varepsilon$ should be between 0.5 and 1.5 standard deviations of the data.
} 
the nonlinearity of returns in majority of the forex markets is not sensitive to structural break. This suggests that the efficiency of most of the forex markets based on nonlinear dependence does not vary with time.

\section{Conclusion}

This study assessed the efficiency of the forex markets of 10 countries in sub-Saharan Africa in the presence of structural break. Using the Kim wild bootstrap joint variance ratio test, it can be observed that only the forex markets of Burundi and Ghana were efficient before and after the structural break and the forex markets of Gambia and Madagascar were not efficient prior to and after structural break. The remaining forex markets produce mixed results taking the presence of structural break into consideration. Without accounting for structural break, the Kim wild bootstrap joint variance ratio test showed that only the Burundian and Ghanaian forex markets were efficient. Employing the BDS independence test, the study showed that all the forex markets were not efficient before structural break but only the Burundian forex market was efficient after the structural break. Ignoring the presence of structural break, the BDS independence test confirmed that all the forex markets are not efficient. The evidence from the forex markets of Burundi, The Gambia, Mauritania, Sierra Leone, Uganda and Zambia supports the Lo's (2004) adaptive market hypothesis which suggests that market efficiency tends to vary with time. These findings offer support for Salisu et al. (2016) and Salisu and Ayinde (2016). The conflicting evidence produced by the linear and nonlinear tests confirms that nonlinearity of returns is a consideration when testing for the efficiency of the selected forex markets. The findings from this study suggest that ignoring structural break and nonlinearity of returns may lead to misleading results when testing for market efficiency.

Table 7: BDS Independence Test with Bootstrapping Results

\begin{tabular}{|c|c|c|c|c|c|c|c|c|c|c|c|}
\hline m & $\varepsilon / \sigma$ & R_BIF & R_GHS & R_GMD & R_MGA & R_MRO & R_MUR & R_MZN & R_SLL & R_UGX & R_ZMW \\
\hline \multicolumn{12}{|c|}{ Pre-break Period } \\
\hline 2 & 0.5 & $0.0000 *$ & $0.0000^{*}$ & $0.0032 *$ & $0.0192^{* *}$ & 0.1768 & $0.0000 *$ & $0.0000 *$ & 0.1392 & $0.0000^{*}$ & $0.0016^{*}$ \\
\hline 3 & 0.5 & $0.0000^{*}$ & $0.0000^{*}$ & $0.0044^{*}$ & $0.0340^{* *}$ & 0.2832 & $0.0000^{*}$ & $0.0000 *$ & $0.0912^{* * *}$ & $0.0008^{*}$ & $0.0000^{*}$ \\
\hline 4 & 0.5 & $0.0000 *$ & $0.0000^{*}$ & $0.0084^{*}$ & $0.0510^{* * *}$ & $0.0924^{* * *}$ & $0.0000^{*}$ & $0.0000 *$ & 0.1554 & $0.0036^{*}$ & $0.0000^{*}$ \\
\hline 5 & 0.5 & $0.0000^{*}$ & $0.0000^{*}$ & $0.0168^{* *}$ & $0.0650 * * *$ & $0.0244^{* *}$ & $0.0000^{*}$ & $0.0000^{*}$ & $0.0976^{* * *}$ & $0.0092^{*}$ & $0.0000^{*}$ \\
\hline 6 & 0.5 & $0.0000^{*}$ & $0.0000^{*}$ & $0.0304^{* *}$ & $0.0794^{* * *}$ & $0.0096^{*}$ & $0.0000^{*}$ & $0.0000^{*}$ & 0.2798 & $0.0116^{* *}$ & $0.0000^{*}$ \\
\hline \multicolumn{12}{|c|}{ Post-break Period } \\
\hline 2 & 0.5 & 0.1998 & $0.0000^{*}$ & $0.0008^{*}$ & $0.0072 *$ & $0.0032^{*}$ & $0.0314^{* *}$ & $0.0068^{*}$ & $0.0000^{*}$ & $0.0584^{* * *}$ & $0.0004 *$ \\
\hline 3 & 0.5 & 0.9280 & $0.0000^{*}$ & $0.0010^{*}$ & $0.0088^{*}$ & $0.0136^{* *}$ & $0.0278^{* *}$ & $0.0052^{*}$ & $0.0000^{*}$ & 0.2052 & $0.0000^{*}$ \\
\hline 4 & 0.5 & 0.7876 & $0.0000 *$ & $0.0020^{*}$ & $0.0028^{*}$ & $0.0584^{* * *}$ & $0.0516^{* * *}$ & $0.0012^{*}$ & $0.0000^{*}$ & 0.3388 & $0.0004^{*}$ \\
\hline 5 & 0.5 & 0.9432 & $0.0000^{*}$ & $0.0030^{*}$ & $0.0016^{*}$ & 0.1408 & $0.0822^{* * *}$ & $0.0020^{*}$ & $0.0000^{*}$ & 0.7892 & $0.0008^{*}$ \\
\hline 6 & 0.5 & 0.9742 & $0.0000^{*}$ & $0.0040^{*}$ & $0.0024^{*}$ & 0.2000 & $0.0940^{* * *}$ & $0.0048^{*}$ & $0.0000^{*}$ & 0.7098 & $0.0004^{*}$ \\
\hline \multicolumn{12}{|c|}{ Full Period } \\
\hline 2 & 0.5 & $0.0000 *$ & $0.0000^{*}$ & $0.0000^{*}$ & $0.0008^{*}$ & $0.0088^{*}$ & $0.0000^{*}$ & $0.0000^{*}$ & $0.0000^{*}$ & $0.0000^{*}$ & $0.0000^{*}$ \\
\hline 3 & 0.5 & $0.0000 *$ & $0.0000 *$ & $0.0000^{*}$ & $0.0008^{*}$ & $0.0392^{* *}$ & $0.0000^{*}$ & $0.0000 *$ & $0.0000^{*}$ & $0.0000^{*}$ & $0.0000 *$ \\
\hline 4 & 0.5 & $0.0000 *$ & $0.0000 *$ & $0.0000^{*}$ & $0.0000^{*}$ & $0.0288 * *$ & $0.0000 *$ & $0.0000 *$ & $0.0000^{*}$ & $0.0000^{*}$ & $0.0000^{*}$ \\
\hline 5 & 0.5 & $0.0000^{*}$ & $0.0000 *$ & $0.0000 *$ & $0.0000^{*}$ & $0.0200^{* *}$ & $0.0000^{*}$ & $0.0000 *$ & $0.0000^{*}$ & $0.0008^{*}$ & $0.0000 *$ \\
\hline 6 & 0.5 & $0.0000^{*}$ & $0.0000 *$ & $0.0008^{*}$ & $0.0000^{*}$ & $0.0104^{* *}$ & $0.0000^{*}$ & $0.0000 *$ & $0.0000^{*}$ & $0.0008^{*}$ & $0.0000^{*}$ \\
\hline
\end{tabular}

Note: ${ }^{* *}$ and ${ }^{* * *}$ indicate the rejection of null hypothesis at $1 \%, 5 \%$ and $10 \%$ significance level and bootstrap p-value for BDS statistic is reported.

Source: Computed by authors

\section{References}

Al-Khazali, O. M. \& Pyun, C. S. (2009). Random walk and martingale difference hypotheses for Pacific Basin foreign exchange markets. 한국재무학회 학술대회, 1698-1727.

Almudhaf, F. (2014). Testing for random walk behaviour in CIVETS exchange rates. Applied Economics Letter, 21(1), 60-63.

Aron, J. (1997). Foreign exchange market efficient tests in South Africa. Oxford: Centre for the Study of African Economies, Department of Economics, University of Oxford.

Azad, A. S. M. S. (2009). Random walk and efficiency tests in the Asia-Pacific foreign exchange markets: Evidence from the post-Asian currency crisis data. Research in International Business and Finance, 23(3), 322-338. 
Azar, S. A. (2014). Martingales in daily foreign exchange rates: Evidence from six currencies against the Lebanese pound. Applied Economics and Finance, 1(1), 55-64.

Baffes, J. (1994). Does co-movement among exchange rates imply market inefficiency? Economic Letters, $44(3), 273-280$.

Belaire-Franch, J. \& Contreras, D. (2002). How to compute the BDS test: A software comparison. Journal of Applied Econometrics, 17(6), 691-699.

Belaire-Franch, J. \& Opong, K. (2005). Some evidence of random walk behaviour of Euro exchange rates using ranks and signs. Journal of Banking and Finance, 29(7), 1631-1643.

Brock, W. A., Dechert, W. D., Scheinkman, J. A. \& LeBaron, B. (1996). A test for independence based on the correlation dimension. Econometric Reviews, 15(3), 197-255.

Brock, W. A., Hsieh, D. A. \& LeBaron, B. D. (1991). Nonlinear Dynamics, Chaos, and Instability: Statistical Theory and Economic Evidence. Cambridge: MIT Press

Campbell, J. Y., Lo., A. W. \& Mackinlay, A. C. (1997). The econometrics of financial markets. New Jersey: Princeton University Press.

Charles, A. \& Darné, 0. (2009). Testing for random walk behaviour in Euro exchange rates. Économie Internationale, $119,25-45$.

Charles, A., Darné, 0. \& Kim, J. H. (2012). Exchange-rate return predictability and the adaptive market hypothesis: Evidence from major foreign exchange rates. Journal of International Money and Finance, 31(6), 1607-1626.

Cheung, A. W., Su, J. \& Choo, A. K. (2012). Are exchange rates serially correlated? New evidence from the Euro FX markets. Review of Financial Economics, 21(1), 14-20.

Chiang, S. M., Lee, Y. H., Su, H. M. \& Tzou, Y. P. (2010). Efficiency tests of foreign exchange markets for four Asian countries. Research in International Business and Finance, 24(3), 284-294.

Czech, K. A. \& Waszkowski, A. (2012). Foreign exchange market efficiency. Empirical results for the USD/EUR market. Finance Internet Quarterly e-Finanse, 8(3), 1-9.

Escanciano, J. C. \& Lobato, I. N. (2009). Testing the martingale hypothesis. In Patterson, K. \& Mills, T. C. (Eds.). Palgrave Handbook of Econometrics (pp.972-1003). Basingstoke: Palgrave Macmillan.

Fama, E. (1970). Efficient capital markets: A review of theory and empirical work. Journal of Finance, 25(2), 383-417.

Gilmore, C. G. (1996). Detecting linear and nonlinear dependence in stock returns: New methods derived from chaos theory. Journal of Business and Finance Accounting, 23(9-10), 1357-1377.

Gradojević, N., Djaković, V. \& Andjelić, G. (2010). Random walk theory and exchange rate dynamics in transition economies. Panoeconomicus, 57(3), 303-320.

Hong, Y. \& Lee, T. (2003). Inference on predictability of foreign exchange rates via generalized spectrum and nonlinear time series models. The Review of Economics and Statistics, 85(4), 1048-1062.

Hsieh, D. A. (1991). Chaos and nonlinear dynamics: Application to financial markets. The Journal of Finance, 46(5), 1839-1877.

Hsieh, D. A. \& LeBaron, B. (1988). Small sample properties of the BDS statistic. In W. A. Brock, D. Hsieh, \& B. LeBaron (Eds.), Nonlinear dynamics, chaos, and instability. Cambridge: MIT Press.

Katusiime, L., Shamsuddin, A. \& Agbola, F. W. (2015). Foreign exchange market efficiency and profitability of trading rules: Evidence from a developing country. International Review of Economics \& Finance, 35(C), 315-332.

Kim, J. H. (2006). Wild bootstrapping variance ratio tests. Economics Letters, 92(1), 38-43.

Kumar, A. S. (2011). Testing the weak form market efficiency in Indian foreign exchange market (MPRA Paper No. 37071). Munich: University Library of Munich.

Lazăr, D., Todea, A. \& Filip, D. (2012). Martingale difference hypothesis and financial crisis: Empirical evidence from European emerging foreign exchange markets. Economic Systems, 36(3), 338-350.

Liu, C. Y. \& He, J. (1991). A variance-ratio test of random walks in foreign exchange rates. The Journal of Finance, 46(2), 773-785.

Lo, A. W. (2004). The adaptive market hypothesis: Market efficiency from an evolutionary perspective. Journal of Portfolio Management, 30(5), 15-29.

Mabakeng, M. E. P. \& Sheefeni, J. P. S. (2014). Examining the weak form efficiency in foreign exchange market in Namibia. International Review of Research in Emerging Markets and the Global Economy, 1(4), 174187. 
Mbululu, D., Auret, C. J. \& Chiliba, L. (2013). Do exchange rates follow random walks? A variance ratio test of the Zambian foreign exchange market. Southern African Business Review, 17(2), 45-66.

Meese, R. A. \& Rogoff, K. (1983). Empirical exchange models of seventies: Do they fit out of sample? Journal of International Economics, 14(1-2), 3-24.

Ogiogio, G. (1994). A statistical analysis of foreign exchange rate behaviour in Nigeria's auction. (AERC Research Paper No. 49). Nairobi: African Economic Research Consortium.

Pandey, V., Kohers, T. \& Kohers, G. (1998). Deterministic nonlinearity in the stock returns of major European equity markets and the Unites States. Financial Review, 33(1), 45-64.

Perron, P. (1997). Further evidence on breaking trend functions in macroeconomic variables. Journal of Econometrics, 80(2), 335-385.

Perron, P. (2006). Dealing with structural breaks. In Palgrave Handbook of Econometrics, 1(2), 278-352.

Phillips, P. C. B. \& Jin, S. (2013). Testing the martingale hypothesis (Cowles Foundation Discussion Paper No. 1912). Connecticut: Cowles Foundation for Research in Economics, Yale University.

Rasekhi, S. \& Shahrazi, M. (2014). Modified R/s and DFA analyses of foreign exchange market efficiency under two exchange rate regimes: A case study of Iran. Iranian Journal of Economic Research, 18(57), 1-26.

Salisu, A. A. \& Ayinde, T. O. (2016). Testing the martingale difference hypothesis (MDH) with structural breaks: Evidence from foreign exchanges of Nigeria and South Africa. Journal of African Business, $17(3), 342-359$.

Salisu, A. A., Oloko, T. F. \& Oyewole, O. J. (2016). Testing the martingale difference hypothesis with structural breaks: Evidence from Asia-Pacific foreign exchange markets. Borsa Istanbul Review, 16(4), 210-218.

Shalari, 0. \& Stringa, A. (2013). Testing the foreign exchange market efficiency for Euro/Albanian lekë during the period 01 January 2002 - 31 December 2012. Journal of Knowledge Management, Economics and Information Technology, 111(4), 1-15.

Sifunjo, E. K., Ngugi, W. R., Ganesh, P. \& Gituro, W. (2008). An analysis of the efficiency of the foreign exchange market in Kenya. Economics Bulletin, 14(2), 1-13.

Tweneboah, G., Amanfo, A. \& Kumah, S. P. (2013). Evidence of market inefficiency and exchange rate predictability in Ghana. Ghanaian Journal of Economics, 1(1), 52-66.

Wickremasinghe, G. B. (2004). Efficiency of foreign exchange markets: A developing country perspective (ABERU Discussion Paper 3). Caulfield: Monash University.

Wright, J. H. (2000). Alternative variance-ratio tests using ranks and signs. Journal of Business and Economic Statistics, 18(1), 1-9.

Yang, J., Su, X. \& Kolari, J. W. (2008). Do Euro exchange rates follow a martingale? Some out-of-sample evidence. Journal of Banking \& Finance, 32(5), 729-740. 